\title{
When a virus turns the Wheel of life
}

\author{
RAKSHA BHAT
}

\section{Abstract}

The Covid-19 pandemic has been a leveller of sorts, across communities, cities, and countries. All healthcare workers are doing their best beyond the call of duty. With many patients recovering and others succumbing every day, they are facing extreme situations. Sometimes, both the good and the bad occur within in a matter of minutes which can be emotionally exhausting. A single Covid-19 test report whether positive or negative has many implications, the rest depends on the healthcare staff who diagnose, treat and more importantly, convey the diagnosis to the patients. Here is an experience of what healthcare workers face and how they handle it. Brave are those who still hold on to their grit and spirit.

For life and death are one, even as the river and the sea are one.

Khalil Gibran ("On Death", from The Prophet, 1923)

As spring sets in, the famous gulmohurs, jacarandas, cassias, frangipani, tabebuias and rain trees which adorn the city of Bangalore burst into full bloom. Meanwhile, the continuing gloom of the global pandemic hangs like a dark cloud around us right from daybreak. Every morning brings a mixture of preparedness and panic for a frontline healthcare worker, having to step out of the confines of home, with the neighbours watching curiously through their windows and balconies and their dear ones waving an anxious goodbye.

The two stories that I would like to share occurred in the course of one of those Covid days in my hospital. I had just finished my laboratory reporting and the Covid-19 task force daily briefing, when we discuss our "To-do" list and "action points" for pandemic management. The hospital has never been this dynamic with frequent changes in protocols and policies. All the hospital staff, despite a hundred personal challenges, are putting in their two hundred precent.

The microbiology section of the laboratory receives a call from Casualty.

\footnotetext{
Author: Raksha Bhat (rakshakbhat@gmail.com), Junior Consultant and Infection Control Officer, Central Laboratory, St Martha's Hospital, Bengaluru, 560001 INDIA.

To cite: Bhat R. When a virus turns the Wheel of life. Indian J Med Ethics. 2021 Apr-Jun; 6(2) NS: 143-144. DOI: 10.20529/IJME.2020.133.

Published online first on December 29, 2020.

Manuscript Editor:Vijayaprasad Gopichandran

Peer Reviewer: Rakhi Ghoshal

C Indian Journal of Medical Ethics 2020
}

"Can I speak to the Microbiologist?" says the Casualty Medical Officer.

"I am on the line" I reply.

"We have a possible Covid-case from a red zone here... and she has expired despite resuscitation. What do we do?"

Decisions at these moments have consequences, for the hospital, for the staff, for the attenders and for the dead. After a moment when my mind goes blank, I recall what I keep telling my hospital staff "This is a pandemic, not an emergency!"

Therefore, we need to follow the set rules and guidelines. I make a call to our Public Relations Officer to find out the procedure. He speaks to the government health officials and the local administration. We decide to follow the new protocol of collecting nasopharyngeal and oral swabs from suspected Severe Acute Respiratory Illness (SARI) death cases as mandated by the government; we plan to collect samples from the lady who had just left the world a few minutes earlier. If the test result is negative, her mortal remains would be handed over to the family; if found positive, the health authorities would take over the funeral procedures and contact tracing, so we are told. We explain this to the patient's family who, thankfully, understand the situation after a detailed counselling by our medical superintendent and me. The medical resident on duty collects the sample; and the laboratory technician with the ambulance driver transports the sample to the designated laboratory. The Casualty staff look after the mortuary arrangements; until the reports come, we have no choice but to wait.

Before leaving, the patient's attendant says with folded hands,

"Thoda dekhiye na. Aap log tho bhagwan samaan hai, jo bolenge theek hi hoga"

["Please look into this issue, you are like gods, whatever you say must be right"]

We acknowledge his remark with a sense of responsibility and helplessness which nobody would want to bear on their shoulders. The hope and belief in his eyes were strong. While there were things on his mind, especially when losing someone dear during a pandemic comes with its own set of procedural issues and complications, he knew we would take care of the situation. There are patients who continue to look up to doctors as their saviours, despite the growing mistrust of the healthcare fraternity especially during this pandemic

A day later.

Her report arrives. 
"Covid-19: Negative."

We hand over the deceased to the family who are then able to carry on with her last rites and rituals

An end to life.

The wheel turns slowly, but it turns.

We go about our duties. The Microbiology section of the laboratory receives a call from the Obstetrics Department.

"Can I speak to the Microbiologist?" says the Resident.

"I am on the line"I reply

"Ma'am, a pregnant patient has come in, she will get admitted today" she adds.

"Ok, we will collect the swab by afternoon, after the ICMR application procedures"I say.

All armed with viral transport media, swabs, ice packs, transport boxes, personal protective equipment we go to the isolation labour room newly designated for asymptomatic pregnant women from containment zones in the city, who are to be tested fifteen days prior to their expected date of delivery.

While I speak to the residents about sample collection, new Covid-19 protocols and infection control measures that are needed, I see this lady in her mid-thirties sitting on the bed staring blankly and lost in deep thought. We go to her and explain the purpose of Covid-19 testing and the entire procedure. In the middle of our conversation, she breaks down:

"Dactre, nange yenu roga illa, na mane horgade hogilla"

["Doctor, I do not have any disease, I haven't gone out of my home"]

Once again, we are trapped in a state of responsibility and helplessness. We try our best to explain that this Covid-19 testing is in the best interest of herself, her baby and the healthcare workers treating her. In fact, the doctors and nurses had themselves been quarantined and tested last week, and all tested negative. This gives her some solace. The Obstetrics resident on duty collects the sample, the laboratory technician with the ambulance driver transports the sample to the designated laboratory. The labour room staff nurses look after the mother-to-be; until the reports come, we have no choice but to wait.

A day later: her report arrives.

"Covid-19: Negative".

She delivers.

A start to a new life.

The wheel turns slowly, but it turns.

\section{Acknowledgment}

The author would like to acknowledge the two patients who taught her about life, death, and the in-between.

\section{APPEAL FOR DONATIONS TO THE FORUM FOR MEDICAL ETHICS SOCIETY}

The Forum for Medical Ethics Society (FMES), publisher of the Indian Journal of Medical Ethics (IJME), appeals to subscribers, contributors, readers, supporters and well-wishers of IJME and FMES to donate to its corpus and towards the publication of IJME. Contributions from both individuals and institutions are welcome.

FMES has published the journal on a shoestring budget, without a break, since 1993. The journal is known for being open access and spearheading discourse aimed at advancing social justice in health and ethics-centred healthcare and health research reform. It is recognised widely as an authoritative resource of knowledge in bioethics and allied areas of enquiry. FMES and IJME have not only sustained themselves but have grown over these past 25 years. Our ever-growing base of readers, contributors, and reviewers enables the publication of multiple and diverse perspectives on wide-ranging topical areas. We have also striven to upgrade the journal technically to keep up with the advances in publishing to widen our reach. This has been possible only because of your steadfast and sustained support.

We are committed to maintaining our editorial independence which is critical to safeguarding the scientific integrity of what we publish. Therefore, wider support from all those who are committed to social justice in health is essential.

FMES is registered under the Societies Registration Act, 1860 (Reg No: Mumbai-218-1995-G.B.B.D.D) and the Bombay Public Trusts Act, 1950 (Reg No: F-17441 Mumbai, 1995), and donations are eligible for tax exemption under Section 80G of the Income Tax Act, 1961

For more details on how to support us, write to admin@ijme.in or visit our website www.ijme.in/subscribe-support/

\section{SUPPORT OPEN-ACCESS ACADEMIC PUBLICATIONS, DONATE TO THE FMES CORPUS FOR THE PUBLICATION OF IJME!}

